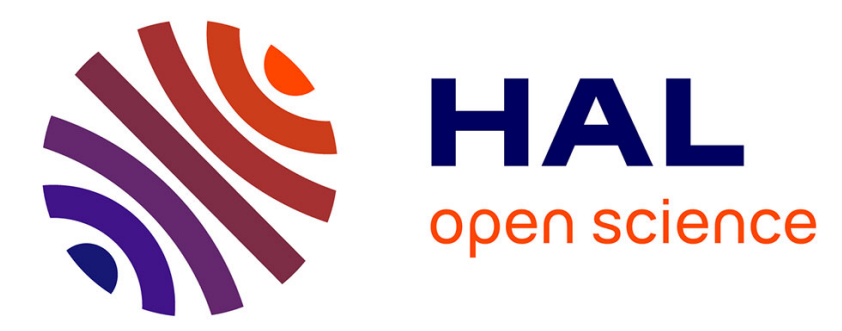

\title{
Particle design Part A: Nucleation kinetics of ketoprofen
} Fabienne Espitalier, Béatrice Biscans, C Laguérie

\section{To cite this version:}

Fabienne Espitalier, Béatrice Biscans, C Laguérie. Particle design Part A: Nucleation kinetics of ketoprofen. Chemical Engineering Journal, 1997, 68 (2-3), pp.95-102. hal-01868720

\section{HAL Id: hal-01868720 https://hal.science/hal-01868720}

Submitted on 5 Sep 2018

HAL is a multi-disciplinary open access archive for the deposit and dissemination of scientific research documents, whether they are published or not. The documents may come from teaching and research institutions in France or abroad, or from public or private research centers.
L'archive ouverte pluridisciplinaire HAL, est destinée au dépôt et à la diffusion de documents scientifiques de niveau recherche, publiés ou non, émanant des établissements d'enseignement et de recherche français ou étrangers, des laboratoires publics ou privés. 


\title{
Particle design Part A: Nucleation kinetics of ketoprofen
}

\author{
F. Espitalier, B. Biscans *, C. Laguérie \\ Laboratoire de Génie Chimique, UMR CNRS 5503, ENSIGC, 18 Chemin de la Loge, 31 078 Toulouse Cedex, France
}

\begin{abstract}
This work is part of a study of the spherical crystallization process by the quasi-emulsion method. The induction time of ketoprofen in acetone + ketoprofen solutions and in solutions of acetone + water + ketoprofen have been experimentally determined. Ketoprofen presents a large metastable zone in the case of primary nucleation and a very narrow metastable zone in the case of secondary nucleation. The rate of primary nucleation in pure acetone has been measured and is correlated by the equation $1.0 \times 10^{36} \exp \left(-2.68 \times 10^{6} / T^{3} \times \ln ^{2} S\right)$ (in number $\mathrm{m}^{3} \mathrm{~s}^{-1}$ ). The physico-chemical properties-phase diagram of the system acetone + water + ketoprofen involved in the process-are given. An experiment to study crystallization into a droplet is presented.
\end{abstract}

Keywords: Crystallization; Nucleation kinetics; Droplet; Mass transfer

\section{Introduction}

In order to improve particle properties, new processes combining granulation and crystallization are being developed. The spherical crystallization process by the quasi-emulsion mechanism is one of these new processes and is applied here to ketoprofen, a pharmaceutical drug. Two solvents are used in this process: acetone and water [1]. Spherical grains made of small crystals of the drug are produced from droplets containing ketoprofen + acetone + water. The grains obtained have adequate properties for direct compression when manufacturing tablets $[2,3]$.

Data of the crystallization kinetics of ketoprofen from a solution in acetone + water mixture are needed to quantify the nucleation and the growth occuring in the droplets initially formed. This work presents the methods used to obtain these data. These results are interpreted by the classical theories of crystallization in solution.

\section{Physico-chemical properties of products}

\section{I. Chemicals}

Ketoprofen $\left(\mathrm{C}_{16} \mathrm{H}_{14} \mathrm{O}_{3}\right)$, i.e., $\alpha$-(3-benzoylphenyl)-propionic acid $( \pm)$, is a well-known antiinflammatory agent. It

\footnotetext{
* Corresponding author.
}

is stable if screened from light. It is not sensitive to temperature variations but it may start to decompose above $340^{\circ} \mathrm{C}$. It is produced from $m$-toluenic acid [4]. The ketoprofen used in this study was produced by Rhône-Poulenc Rorer, France and had a minimum purity of $99.9 \%$.

Ketoprofen crystallizes in a triclinic form. The atomic coordinates of the solid crystal used have been given by Briard and Rossi [5], from a crystallographic study and are: $\mathrm{a}=3.893 \AA, \mathrm{b}=7.741 \AA, \mathrm{c}=6.136 \AA$ and $\alpha_{1}=89.61^{\circ}$, $\beta_{1}=94.56^{\circ}, \gamma_{1}=88.78^{\circ}[5]$.

Synthesis grade acetone from Société de Distribution de Service et de Recherche had a minimum purity of $99.7 \%$; these chemicals were used without further purification. Bidistilled water was used. The mowiol 8-88, a polyvinylic alcohol, has been purchased from Hoechst.

\subsection{Solubilities}

In a previous study, the solubility of ketoprofen in water, acetone and acetone + water was measured and modellcd at various temperatures and atmospheric pressure [6]. The solubility diagram exhibits five regions: one homogeneous, three two-phase (two liquid-solid and one liquid-liquid equilibria) and one three-phase zones. The different one-phase, two-phase and three-phase regions are indicated on Fig. 1 by the regions I, II and III. This figure represents the phase diagram at $20^{\circ} \mathrm{C}$. The same trends have been observed for other temperatures $\left(10,30\right.$ and $\left.50^{\circ} \mathrm{C}\right)$. 


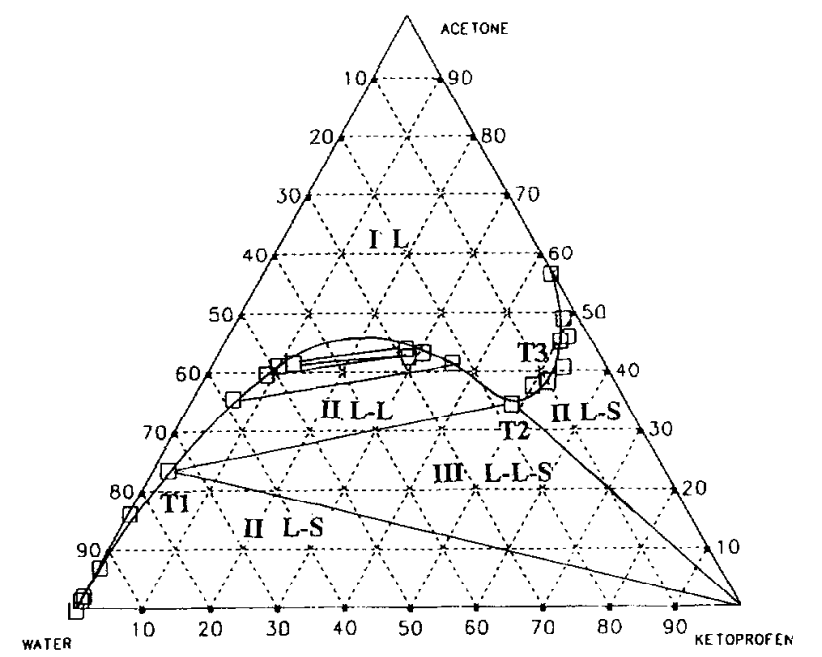

Fig. 1. Ternary diagram of ketoprofen + acetone + water, five different zones: one Liquid area (L). two Liquid-Solid equilibria area, one LiquidI iquid equilihrium area and one Liquid--Liquid-Solid equilibrium area.

The solubilities of ketoprofen in the pure solvent increase when temperature increases. These solubilities are high in pure acetone $\left(0.360 \mathrm{~kg}\right.$ ketoprofen $(\mathrm{kg} \text { solution })^{-1}$ at $10.1^{\circ} \mathrm{C}$ and $0.677 \mathrm{~kg}$ ketoprofen ( $\mathrm{kg}$ solution) ${ }^{-1}$ at $49.3^{\circ} \mathrm{C}$ ) and very low in pure water $\left(86 \mathrm{ppm}\right.$ at $9.8^{\circ} \mathrm{C}$ and $225 \mathrm{ppm}$ at $30^{\circ} \mathrm{C}$ ).

In the case of the ternary system, in the liquid-solid regions the solubility of ketoprofen increases with temperature. For low mass fraction of acetone, $R_{\mathrm{a}}$, the solubility of the drug increases with this mass ratio. Liquid-liquid zones are obtained for acetone mass fraction in the range 0.22 and 0.67 $\mathrm{kg}$ acetone $(\mathrm{kg} \text { acetone }+ \text { water })^{-1}$ mixture. When this ratio is higher than $0.67 \mathrm{~kg}$ acetone $(\mathrm{kg} \text { acetone }+ \text { water })^{-1} \mathrm{mix}-$ ture, the solubility reaches a maximum for a value between 0.86 and $0.93 \mathrm{~kg}$ acetone $(\mathrm{kg} \text { acetone }+ \text { water })^{-1}$ mixture.

\subsection{Supersaturation}

Fig. 2 presents the solubility of ketoprofen in acetone + water mixture as a function of temperature for mass ratio $R_{\mathrm{a}}$ ranged between 0.65 and $1 \mathrm{~kg}$ acetone $(\mathrm{kg}$ acetone + water $)^{-1}$ mixture. This figure shows that the supersaturation state of a ketoprofen + acetone solution can be reached by cooling. However, this state cannot be reached by addition of water at constant temperature if the mass ratio $R_{\mathrm{a}}$ stays higher than $0.67 \mathrm{~kg}$ acetone $(\mathrm{kg} \text { acetone }+ \text { water })^{-1}$ mixture. But for mass ratio lower than 0.67 , an aqueous phase appears so that two liquid phases exist (hatched areas on Fig. 2). Further experiments have shown that the appearance of this second liquid phase by addition of water at constant temperature leads to crystallization of ketoprofen [1].

\section{Primary nucleation}

\subsection{Experimental methods}

A direct measurement of nucleation kinetics is rather difficult. Therefore the use of indirect methods is prefered. These

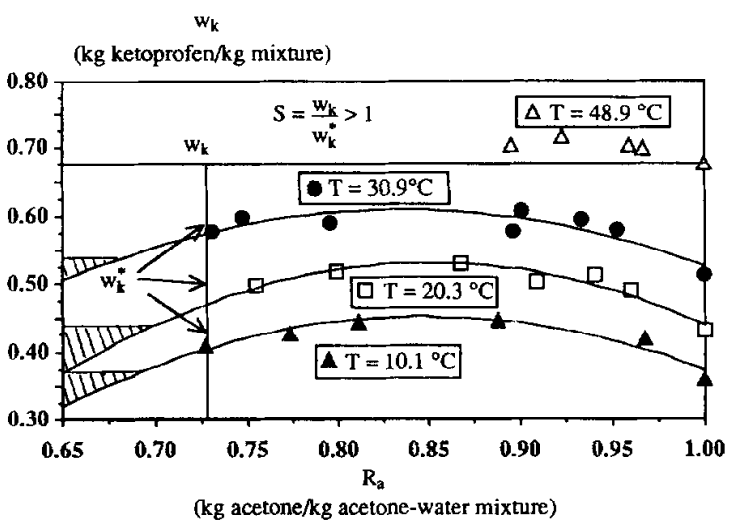

Fig. 2. Ternary diagram of ketoprofen + acetone + water: Liquid-Solid equilibria area for mass ratio $\mathrm{Ra}$ between 0.65 and $1 \mathrm{~kg}$ acetone $(\mathrm{kg}$ acetone + water) $)^{-1}$ mixture.

mainly consist either in crystallization experiments based on the population density balance or in evaluating experimental data on the induction time or the metastable zone width. The results of data evaluation from the former depend considerably on the degree of simplification accepted when solving the population balance. The latter methods are fairly simple with respect to the equipment and experimental procedure [7].

The primary nucleation kinetics were determined from metastable zone width measurements and induction times. Nucleation experiments were carried out in a cylindrical glass cell, $100 \mathrm{~cm}^{3}$ in capacity, magnetically stirred. The temperature was controlled at $\pm 0.1^{\circ} \mathrm{C}$ by circulating thermostated water in the jacket.

\subsubsection{Metastable zone}

The experimental procedure consists in slowly cooling a saturated solution until nucleation is detected. So, a solution was prepared from weighed amounts of ketoprofen, acetone and water, and dissolved at a temperature slightly higher than the solubility temperature. Then, this solution was cooled at a constant rate until the first nuclei were detected visually. Assuming that the initial growth rate of the nuclei is very rapid, a lighting system enables the detection of the cloud in the mixture characteristic of the nuclei birth. The position of the metastability boundary is expressed by the maximal attainable undercooling, which corresponds to the maximal attainable supersaturation.

\subsubsection{Induction time}

A different method for assessing the nucleation kinetics is the measurement of the induction period. Nucleation does not occur instantaneously when supersaturation has been created in a solution. The induction time, $\tau$, is the time that elapses between the achievement of supersaturation and the appearance of a solid phase in a given system.

$\tau$ is a complex quantity which is rarely dependent only on nucleation. This time is affected mainly by the supersaturation of the solution, the temperature, the agitation, the presence of both soluble and insoluble impurities and the volume 
of solution. The smaller the volume of solution, the higher the induction time [8].

The experimental procedure consists in establishing a desired supersaturation as quickly as possible and once this supersaturation is achieved, to maintain the solution at a constant temperature. The time between the supersaturation achievement and the detection of the first crystals visually is measured and regarded as $\tau$.

Induction times have been measured in pure acetone and in acetone-water mixtures. The solution of ketoprofen, contained in a reactor of $100 \mathrm{~cm}^{3}$, is initially maintained at $50^{\circ} \mathrm{C}$ and stirred for about $1 \mathrm{~h}$. In the pure acetone, the initial concentration is $0.651 \pm 0.007 \mathrm{~kg}$ ketoprofen ( $\mathrm{kg}$ solution $)^{-1}$. In that case, the initial temperature of the solution $\left(50^{\circ} \mathrm{C}\right)$ was quickly decreased by replacing the water circulating in the jacket of the vessel by a colder one. This procedure was adopted to simulate the thermal shock to which the solution is subjected in the studied process ( see part B of the study). Then, the organic solution rapidly reaches a stable temperature $T$ at which induction time measurements are carried out. Consequently, the cooling was performed in a time that was negligible compared with induction time (about 1 or $2 \mathrm{~min}$ ). The measurements were carried out at final temperatures ranging from 18.8 to $35.5^{\circ} \mathrm{C}$. The experimental procedure is not applicable for undercooling greater than $31.2^{\circ} \mathrm{C}$ because the induction time then becomes shorter than the time of cooling.

Due to the different procedures of creation of undercooling in the metastable zones measurements, in the one hand, and in the induction times measurements, in the other hand, the maximum attainable undercooling are not in the same ranges. That is why the undercooling values obtained in the induction times measurements are higher than for metastable zones measurements.

\subsection{Results}

The experimental results of metastable zone width measurements obtained at cooling rates in the range $0.24-0.48^{\circ} \mathrm{C}$ $\min ^{-1}$ are shown in Table 1 and in Fig. 3. A large metastable zone of about $16.7 \pm 1.8^{\circ} \mathrm{C}$ is obtained. If some crystals were added to a supersaturated solution of acetone + water $(400$ $\mathrm{ml}$ ) contained in a mechanically stirred and thermostated reactor, then a few minutes after the introduction of crystals $(0.6 \mathrm{~g})$, a dense cloud appears in the reactor. This cloud is characteristic of nucleation. This sort of nucleation is called secondary nucleation [9]. This secondary nucleation has

Table 1

Limit supersaturation temperature of saturated acetone-ketoprofen solution

\begin{tabular}{llll}
\hline $\begin{array}{l}\text { Cooling rate } \\
\left({ }^{\circ} \mathrm{C} / \mathrm{min}\right)\end{array}$ & $\begin{array}{l}w_{\mathrm{k}}(\mathrm{kg} \text { ketoprofen } \\
\left.(\mathrm{kg} \text { solution })^{-1}\right)\end{array}$ & $T_{\text {sat }}\left({ }^{\circ} \mathrm{C}\right)$ & $T_{\lim }\left({ }^{\circ} \mathrm{C}\right)$ \\
\hline 0.48 & 0.599 & 39.8 & 21.3 \\
0.37 & 0.511 & 29.0 & 11.5 \\
0.24 & 0.426 & 18.4 & 4.2 \\
\hline
\end{tabular}

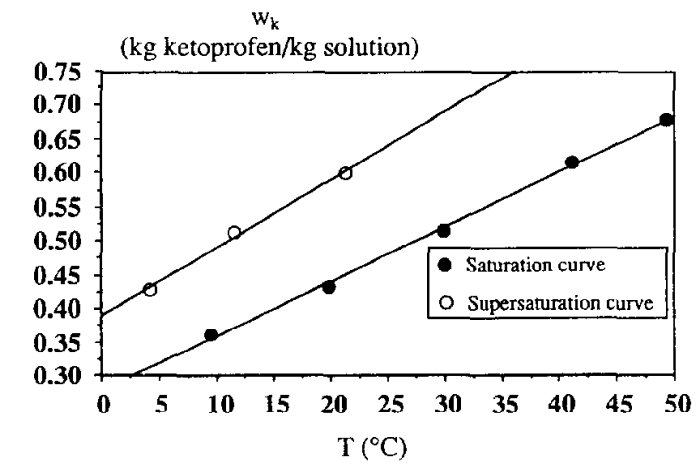

Fig. 3. Metastable zone of ketoprofen + acetone solution obtained with a cooling rate between 0.2 and $0.5^{\circ} \mathrm{C} / \mathrm{min}$.

Table 2

Induction time, $\tau$, of acetone-ketoprofen mixtures

\begin{tabular}{llll}
\hline$\Delta T\left({ }^{\circ} \mathrm{C}\right)$ & $T\left({ }^{\circ} \mathrm{C}\right)$ & $S(-)$ & $\tau(\mathrm{s})$ \\
\hline 10.7 & 35.6 & 1.128 & 8429 \\
13.1 & 33.2 & 1.169 & 6918 \\
16.3 & 30.0 & 1.234 & 5106 \\
16.7 & 29.6 & 1.261 & $3505-6589$ \\
18.4 & 27.9 & 1.271 & $>11,458$ \\
20.0 & 26.3 & 1.308 & $>8793$ \\
20.4 & 25.9 & 1.314 & 2235 \\
21.2 & 25.1 & 1.336 & 1939 \\
21.3 & 25.0 & 1.338 & 1423 \\
22.2 & 24.1 & 1.339 & 713 \\
22.5 & 23.8 & 1.395 & $1247-2334$ \\
25.6 & 20.7 & 1.448 & $4626-4632$ \\
26.9 & 19.4 & 1.472 & 1272 \\
30.3 & 16.0 & 1.589 & 905 \\
30.7 & 15.6 & 1.601 & 3411 \\
31.2 & 15.1 & 1.630 & 896 \\
\hline
\end{tabular}

been obtained even for low supersaturation ratios. It seems that the metastable zone, which is very large in the case of primary nucleation, is very narrow in the case of secondary nucleation.

The operating conditions using pure acetone and results of the induction time measurements are presented in Table 2. The induction times are very high $(>1 \mathrm{~h})$ when the supersaturation ratio is lower than 1.31. For supersaturation ratios higher than 1.63 , induction time are generally lower than 8 min. The ratios 1.31 and 1.63 correspond to undercoolings, $\Delta T$, equal to 20 and $31.2^{\circ} \mathrm{C}$, respectively. For an undercooling greater than $21^{\circ} \mathrm{C}$, the induction time remains quasi constant for crystallization from pure acetone.

In the acetone + water mixture, the induction times have been measured for solutions saturated at $45.6 \pm 0.2^{\circ} \mathrm{C}$. The results are shown in Table 3 . Fig. 4 presents the induction time as a function of the under-cooling $\Delta T$, and the acetone ratio, $R_{\mathrm{a}}$. The induction time decreases when the under-cooling increases whatever the acetone ratio. Moreover, the increase of the percentage of water in the mixture increases the induction time. This tendency can be explained by the viscosity of solutions. Previous experimental studies have shown that the viscosity of acetone + water mixtures is higher 
Table 3

Induction time of acetone-water-ketoprofen solutions

\begin{tabular}{llll}
\hline$\Delta T\left({ }^{\circ} \mathrm{C}\right)$ & $\begin{array}{l}R_{\mathrm{a}}(\mathrm{kg} \text { acetone } \\
(\mathrm{kg} \text { acetone }+ \text { water })^{-1}\end{array}$ & $S(-)$ & $\tau(\mathrm{s})$ \\
& mixture & \\
\hline 24.3 & 0.963 & 1.373 & 5805 \\
30.0 & 0.964 & 1.464 & 995 \\
30.0 & 0.965 & 1.467 & 335 \\
30.1 & 0.964 & 1.509 & 1121 \\
35.8 & 0.966 & 1.676 & 1117 \\
20.6 & 0.893 & 1.229 & $>14,805$ \\
21.0 & 0.897 & 1.445 & $>9107$ \\
30.5 & 0.891 & 1.422 & 4463 \\
36.5 & 0.894 & 1.568 & 1915 \\
36.7 & 0.894 & 1.570 & 3398 \\
30.4 & 0.800 & 1.416 & 11,595 \\
38.1 & 0.801 & 1.654 & 2342 \\
\hline
\end{tabular}

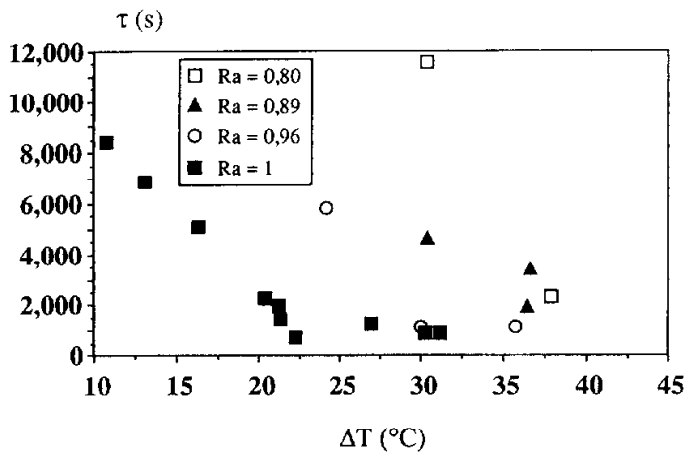

Fig. 4. Induction time in accordance with the difference of temperature and the mass ratio acetone + water.

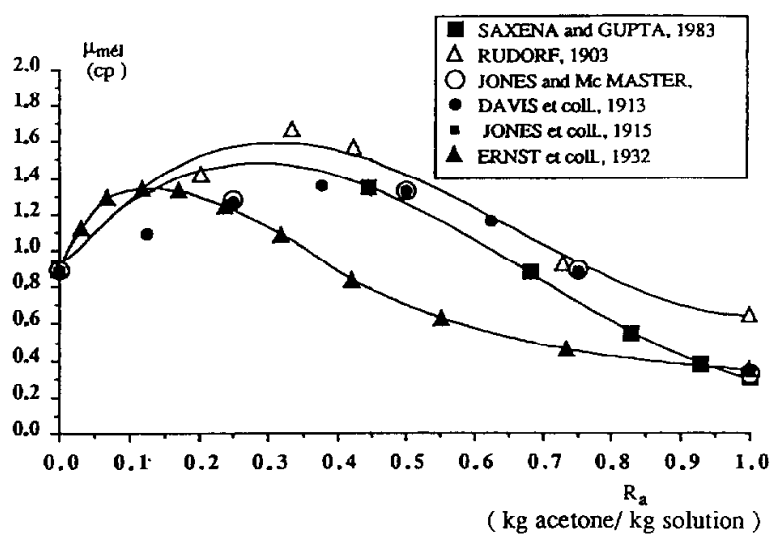

Fig. 5. Viscosities of acetone + water solution as a function of mass ratio $\mathrm{Ra}$ from Ref. [10].

than the viscosity of pure acetone at $25^{\circ} \mathrm{C}[10]$. Fig. 5 shows the values of viscosities of acetone + water mixtures obtained by several authors [10]. This increase of viscosity is pronounced by the presence of ketoprofen in solution. Moreover, with constant agitation, an increase of viscosity leads to a decrease of impacts number between the molecules in solution, and hence to an increase of induction time.

\section{Primary nucleation rate}

Induction time is a complex quantity which is rarely dependent only on nucleation. Nevertheless, despite its complexity the induction period has frequently been used as a measurement of the nucleation event, making the simplifying assumption that it can be considered to be inversely proportional to the rate of nucleation [9]:

$\tau=k_{1} / J_{1}$

The classical rate of new phase formation by nucleation is given by Ref. [8]:

$J_{1}=B_{1} \exp \left(-\frac{\Delta G_{n}^{*}}{k_{\mathrm{B}} T}\right)$

$B_{1}$ is a constant which has been approximated by Nielsen [10] as:

$B_{1}=\frac{D_{\mathrm{km}}}{d^{5}}\left(\frac{2 \ln S}{3 \pi n^{*}}\right)^{1 / 2}$

One can write:

$J_{1}=B_{1} \exp \left(-\frac{A_{1}}{T^{3} \ln ^{2} S}\right)$

where $A_{1}$ is given by the following equation:

$A_{1}=\frac{\xi \sigma_{\mathrm{s}}^{3} V_{\mathrm{m}}^{2}}{k_{\mathrm{B}}^{3}}$

where $\xi$ is the shape factor $\left(\xi=4 / 27 \times \beta^{3} / \alpha^{2}\right)$.

Combining Eq. (4) with Eq. (1) gives:

$\ln \tau=\ln \left(k_{1} / B_{1}\right)+\frac{A_{1}}{T^{3} \ln ^{2} S}$

At fixed conditions of agitation, the plot of $(\ln \tau)$ against $\left(T^{-3}(\ln S)^{-2}\right)$ should be linear. The interfacial energy, $\sigma_{s}$, is evaluated from the slope of this curve. Fig. 6 gives a representation of this for the case of pure acetone. The used temperature for each trial is reported in Table 2. As shown in the figure, deviations from the classical behaviour described by Eq. (6) occur at low supersaturation. In reality, two straight lines are shown. The change of slope is observed for an $S$ value of 1.311: the homogeneous nucleation may pro-

$\ln \tau$

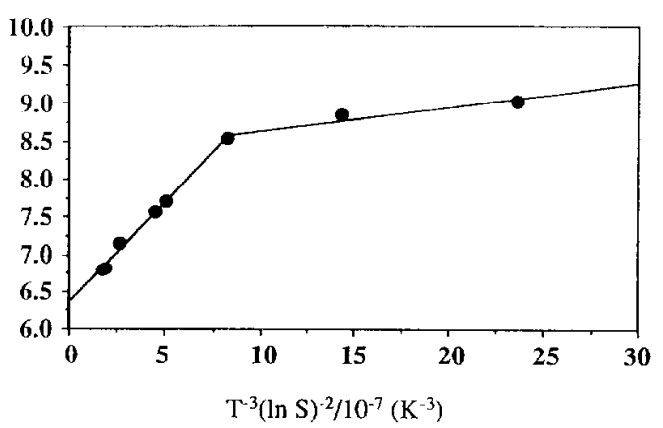

Fig. 6. Estimation of the interfacial energy crystal-solvent (acetone). 
gressively change to heterogeneous nucleation as supersaturation is decreased $[9,11]$.

Heterogeneous nucleation occurs at lower supersaturations than the homogeneous one. So, in general, the induction time for heterogeneous nucleation is smaller than for homogeneous nucleation. The sharp increase in the particle number with increasing supersaturation is characteristic on the onset of homogeneous nucleation.

In the homogeneous nucleation zone, experimental data can be correlated by the following equation:

$\ln \tau=6.3528+\frac{2.6817 \times 10^{6}}{T^{3} \ln ^{2} S}$

with a coefficient of correlation equal to 0.997 .

So $A_{1}$ is equal to $2.6817 \times 10^{6}\left(\mathrm{~K}^{3}\right)$. For a spherical nucleus, the surface shape factor, $\beta$, and the volume shape factor, $\alpha$, are $\pi$ and $\pi / 6$, respectively. The molecular volume of the ketoprofen is equal to $3.64 \times 10^{-28} \mathrm{~m}^{3}$ molecule ${ }^{-1}$. The calculated interfacial energy crystal-solution, $\sigma_{\mathrm{s}}$, is $1.47 \times 10^{-3} \mathrm{~N} \mathrm{~m}^{-1}$ for a temperature ranging between 14 and $30^{\circ} \mathrm{C}$. This value can be compared with values reported in the litterature for other materials, for about the same range of temperature: $7.2 \times 10^{-3} \mathrm{~N} \mathrm{~m}^{-1}$ for $n$-heptadecane, $9.6 \times 10^{-3} \mathrm{~N} \mathrm{~m}^{-1}$ for $n$-octadecane, $8.3 \times 10^{-3} \mathrm{~N} \mathrm{~m}^{-1}$ for $n$-tetracosane [12]. The $\sigma_{\mathrm{s}}$ value obtained in this study is lower than the previous ones, may be because with our type of molecule, the nucleation centres are more active.

For the constant $B_{1}$, authors give as an approximation the following relation $[11]$ :

$B_{J_{1}}=\frac{D_{\mathrm{sj}}}{V_{\mathrm{m}}^{5 / 3}}$

We have calculated the diffusion coefficient of ketoprofen in the binary system (acetone + ketoprofen) from the empirical Gordon equation established in the case of electrolytic solutions. We have modified this equation because empirical relations for diffusion in concentrated media do not exist. In the case of electrolytic solutions, the following equation is proposed by several authors [13]:

$D_{\mathrm{sj}}=D_{\mathrm{sj}}^{{ }_{\mathrm{\alpha}}} \frac{\mu_{\mathrm{solv}}}{\mu} \frac{V}{n_{\text {solv }} V_{\text {solv }}}\left(1+m \frac{\partial \ln \gamma^{ \pm}}{\partial m}\right)$

So, the diffusion coefficient in a concentrated liquid can be calculated with the equation:

$D_{\mathrm{kil}}=D_{\mathrm{ka \textrm {a }}}^{\infty} \frac{\mu_{\mathrm{solv}}}{\mu} \frac{V}{n_{\mathrm{solv}} V_{\mathrm{solv}}}\left(1+x_{\mathrm{k}} \frac{\partial \ln \gamma_{\mathrm{k}}}{\partial x_{\mathrm{k}}}\right)$

The volume of solution is calculated by assuming the additivity of acetone and ketoprofen volumes.

The infinite dilute diffusion coefficient $D_{\mathrm{ka}}^{\infty}$ has been calculated by the Reddy and Doraiswamy equation [14]:

$D_{\mathrm{kax}}=k_{2} \frac{M_{\mathrm{a}}^{0.5}}{v_{\mathrm{k}}^{\prime 1 / 3} v_{\mathrm{i} 1}^{\prime 1 / 3}} \frac{T}{\mu_{\mathrm{a}}}$ with: $k_{2}=3.16 \times 10^{-17}$ if $V_{\mathrm{k}}^{\prime} / V_{\mathrm{a}}^{\prime} \geq 1.5 ; k_{2}=2.69 \times 10^{-17}$ if $V^{\prime}{ }_{k} / V^{\prime}{ }_{a}<1.5$.

The molar volumes at the normal boiling points are obtained by additivity of the Lebas additive-volume increments of atoms or groups of atoms [14]. They are equal to $74 \times 10^{-6} \mathrm{~m}^{3} \mathrm{~mol}^{-1}$ and $320 \times 10^{-9} \mathrm{~m}^{2} \mathrm{~mol}^{-1}$, respectively.

At $23^{\circ} \mathrm{C}$ and a viscosity of acetone equal to $0.31 \times 10^{-3}$ Pa s [15], the infinite dilute diffusion coefficient of ketoprofen is $2.5 \times 10^{-9} \mathrm{~m}^{2} \mathrm{~s}^{-1}$.

The activity coefficient of ketoprofen in acetone + ketoprofen solution is calculated by the UNIQUAC model [6]. The derivative of this coefficient, $\partial \ln \gamma_{k} / \partial x_{k}$, js evaluated by second order finite difference. The derivation corresponding to a concentration of $0.651 \mathrm{~kg}$ ketoprofen $(\mathrm{kg}$ solution $)^{-1}$ is 1.108 . The calculated diffusion coefficient is $1.9 \times 10^{-10} \mathrm{~m}^{2} \mathrm{~s}^{-1}$. So, finally, the kinetic constant, $B_{1}$ of Eq. (2) is equal to $1.02 \times 10^{36}$ number, $\mathrm{m}^{3} \mathrm{~s}^{-1}$.

\section{Visualization of crystallization by the quasi-emulsion process}

Ketoprofen is crystallized by the quasi-emulsion process enabling us to obtain spherical grains (see part B of this work). The crystallization takes place in droplets made of ketoprofen + acetone immersed in aqueous solution. Crystals of ketoprofen nucleate and grow inside each droplet leading to spherical solid grains made up of many small agglomerated crystals.

In order to reproduce the phenomena occuring in each droplet generated in the process and to have an idea of the order of magnitude of the induction time of ketoprofen in this droplet, a different experiment has been used.

The apparatus used, originally set up to measure the contact angle [16] is made up of several sections: (i) An experimental unit consists of a hollow cylinder of PTFE with glass windows on two facing sides. This apparatus forms the container in which the aqueous solution and droplet of acetone + ketoprofen are placed. This system is maintained at a constant temperature; (ii) A high resolution video camera is used to record the droplet; (iii) The droplet support, immersed in the aqueous phase, consists of a horizontal steel plate; (iv) A data acquisition card receives the video signal from the camera.

The experiment consists of placing a droplet of saturated solution of ketoprofen + acetone initially prepared at $50^{\circ} \mathrm{C}$ (the mass fraction of ketoprofen being $1.92 \mathrm{~kg}$ ketoprofen ( $\mathrm{kg}$ solution $)^{-1}$ ), on the support set inside an aqueous solution containing 203 ppm of mowiol 8-88 using a syringue. The mowiol $8-88$ is a polyvinylic alcohol used as an emulsifier. The droplet volume is $10 \mu$. The stagnant aqueous solution is maintained at $20^{\circ} \mathrm{C}$ in the experimental unit. Of course, the conditions of creation of the single droplet are quite different in this experiment, from those carried out in the process, because the droplet is stagnant for vizualization 


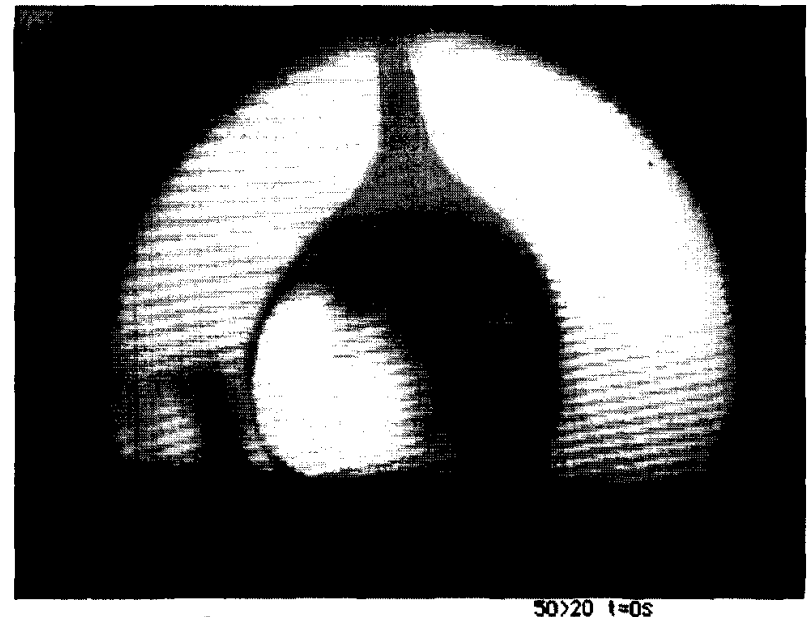

$50>201=05$

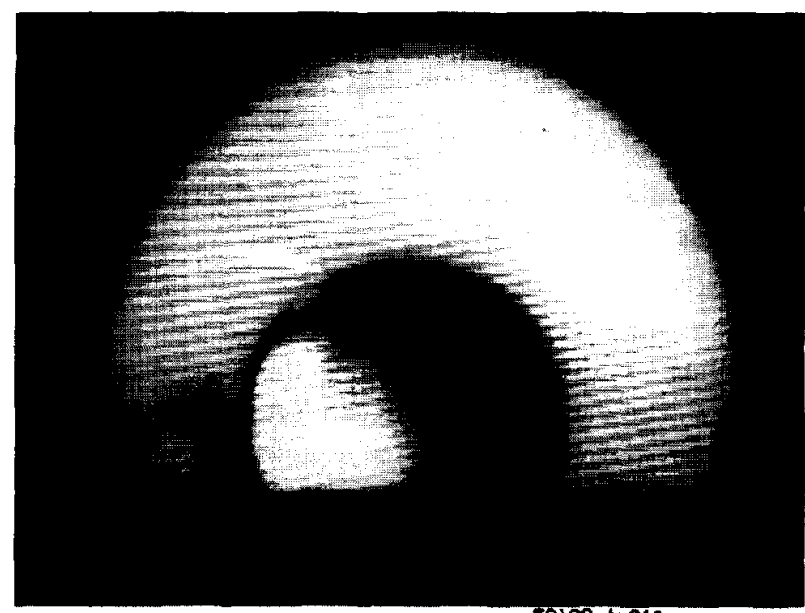

$30220 t=315$

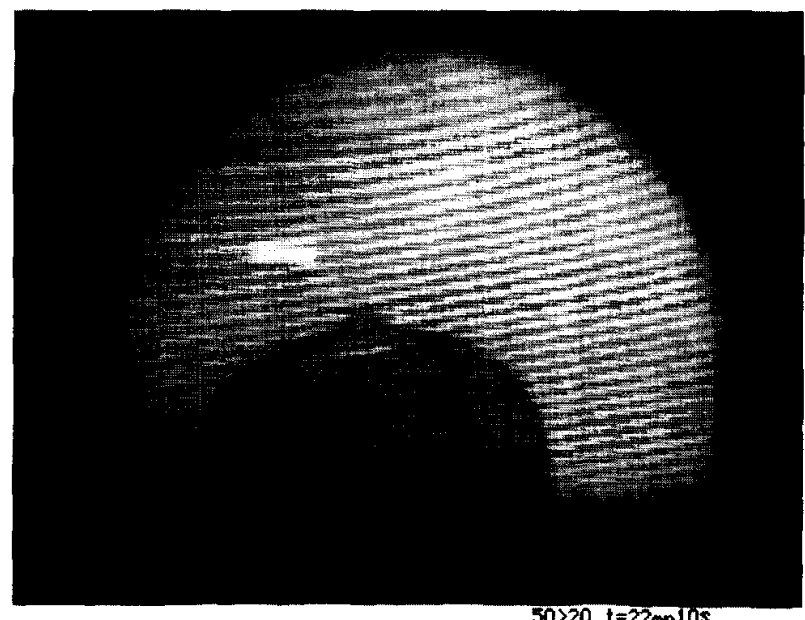

$50>20 t=22 \min 10 \mathrm{~s}$

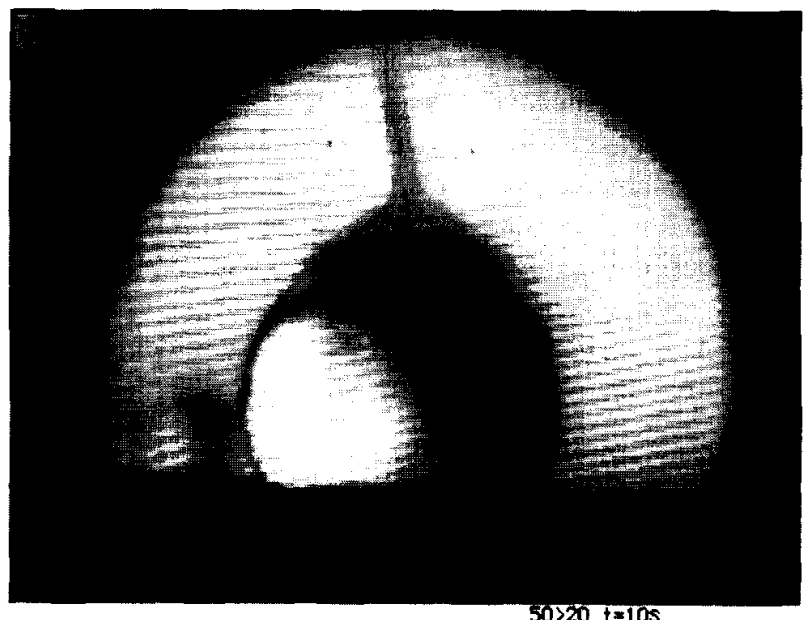

$50>20 t=105$

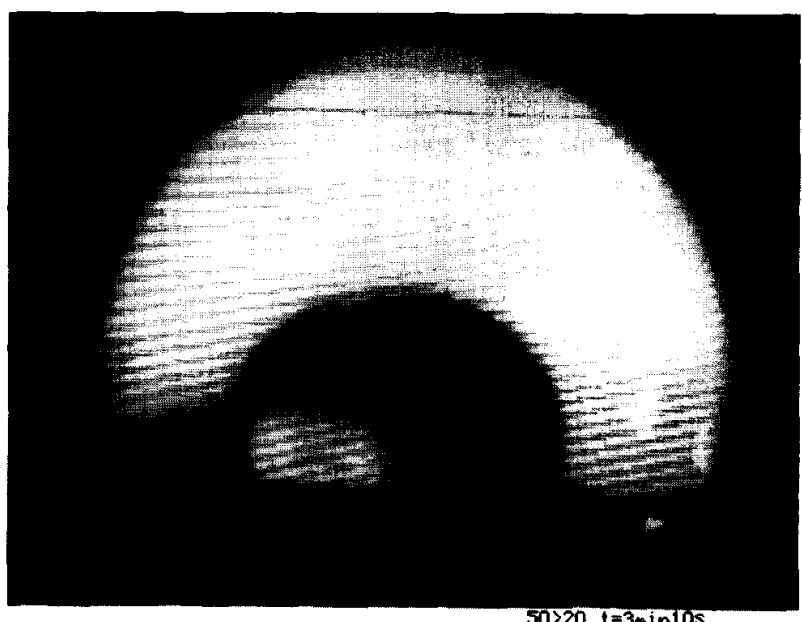

$50>20 t=3 m$ inios

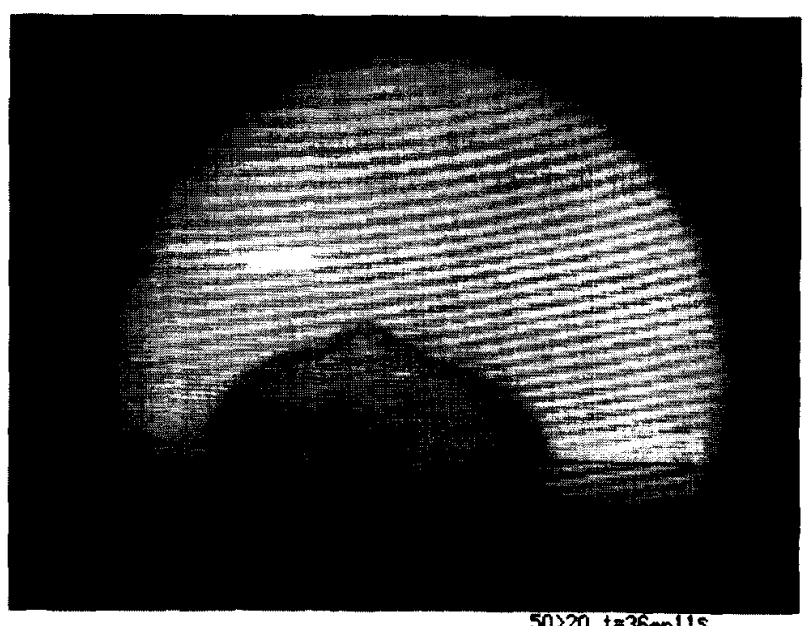

$50>20 t=36 \min 11 \mathrm{~s}$

Fig. 7. Experimenl with a droplet: Inass transfer and cooling, induction time and crystallization.

purposes (a population of moving droplets (emulsion) is generated in the actual process).

Fig. 7 shows the development of the droplet versus time. Three steps can be observed: first, transfer of acetone in the continuous phase, then the latent time between the end of mass transfer, and the third step, the crystallization of ketoprofen. As soon as the droplet is laid down, we observe a film and a flux of acetone at the top of the droplet ( $a$ and $b$ ). The presence of the film is due to the absence of agitation in the continuous phase. Acetone transfer is not detected beyond ten seconds (c). The first crystals appear after roughly twenty minutes at the surrounding of the droplet (e) develop inwards. After $36 \mathrm{~min}$, the droplet is solid and has an anisotropic shape (f). The previous durations are taken as exam- 
ples of results. Several trials have been made leading to bad reproducibility, mainly due to the difficulty to create exactly the same droplet in each case. Nevertheless, the orders of magnitude of the induction times obtained in a droplet of 10 $\mu l$ are different from those obtained in a reactor of $100 \mathrm{ml}$.

It is difficult to transpose in a laboratory scale reactor the conditions of creation of the supersaturation inside the droplet. Moreover, the parameters influencing the nucleation and the growth in a droplet of $(0.01-0.050 \mathrm{ml})$ are numerous and are difficult to reproduce in a batch reactor $(0.1-0.21)$. The induction times in the droplets are function of the supersaturation ratio and of the supersaturation creation rate, and these two variables are functions of the mass transfer kinetics.

\section{Conclusion}

Primary nucleation rates of ketoprofen can be determined by measuring the induction periods corresponding to several values of supersaturation, using temperature variation. Ketoprofen presents a large metastable zone in the case of primary nucleation and a very narrow metastable zone in presence of ketoprofen crystals.

The rate of primary nucleation of ketoprofen in pure acetone has been measured and correlated by the equation: to $1.0 \times 10^{36} \exp \left(-2.68 \times 10^{6} / T^{3} \mathrm{ln}^{2} S\right)$ number, $\mathrm{m}^{-3} \mathrm{~s}^{-1}$.

The phenomena occuring in one droplet isolated in stagnant conditions were observed by means of a specific experiment. Crystallization of ketoprofen by the quasi-emulsion process is developed elsewhere (part B of this work).

\section{Acknowledgements}

The authors wish to acknowledge Rhône-Poulenc Rorer and the French Minitère de l'Enseignement Supérieur et de la Recherche (MESR) for their financial supports to this project.

\section{Appendix A. Nomenclature}

\section{$a, b, c \quad$ Atomic coordinates $(\AA)$}

$A_{1} \quad$ Constant $\left(\mathrm{K}^{3}\right)$

$B_{1} \quad$ Constant of primary nucleation rate (number of nuclei, $\mathrm{m}^{-3} \mathrm{~s}^{-1}$ )

$d \quad$ Mean molecular diameter of the growth unit $(\mathrm{m})$

$D_{\mathrm{s} j}^{\infty} \quad$ Diffusion coefficient of solute $s$ in solvent $\mathrm{j}$ at infinite dilute $\left(\mathrm{m}^{2} \mathrm{~s}^{-1}\right)$

$D_{\mathrm{ka}}^{\infty} \quad$ Diffusion coefficient of ketoprofen in acetone at infinite dilute $\left(\mathrm{m}^{2} \mathrm{~s}^{-1}\right)$

$D_{\mathrm{ka}} \quad$ Diffusion coefficient of ketoprofen in acetone $\left(\mathrm{m}^{2}\right.$ $s^{-1}$ )

$D_{\mathrm{km}} \quad$ Diffusion coefficient of ketoprofen in mixture $\left(\mathrm{m}^{2}\right.$ $\left.s^{-1}\right)$
$J_{1} \quad$ Rate of nucleation (number of nuclei, $\mathrm{m}^{-3} \mathrm{~s}^{-1}$ )

$k_{\mathrm{B}} \quad$ Boltzmann constant ( $\mathrm{J}$ molecule $\mathrm{e}^{-1} \mathrm{~K}^{-1}$ )

$k_{1} \quad$ Proportional constant (number of nuclei, $\mathrm{m}^{-3}$ )

$k_{2} \quad$ Constant ( - )

$n^{*} \quad$ Critical nucleus size $(\mathrm{m})$

$n_{\text {solv }} \quad$ Number of moles of solvent in the solution volume $\left(\mathrm{m}^{3}\right)$

$m \quad$ Molality of solute $\left(\mathrm{mol} \mathrm{m} \mathrm{m}^{-3}\right)$

$M_{a} \quad$ Molar weight of acetone $\left(\mathrm{g} \mathrm{mol}^{-1}\right)$

$R_{\mathrm{a}} \quad$ Acetone ratio in acetone + water mixture $(\mathrm{kg}$ acetone $(\mathrm{kg} \text { acetone }+ \text { water })^{-1}$ mixture $)$

$S \quad$ Supersaturation ratio (-)

$T \quad$ Temperature (K)

$T_{\mathrm{lim}} \quad$ Limit supersaturation temperature $\left({ }^{\circ} \mathrm{C}\right)$

$T_{\text {siat }}$ Saturation temperature $\left({ }^{\circ} \mathrm{C}\right)$

$V \quad$ Partial molar volume of solution $\left(\mathrm{m}^{3}\right)$

$V_{a}^{\prime} \quad$ Molar volume of acetone at the normal boiling point $\left(\mathrm{cm}^{3} \mathrm{~mol}^{-1}\right)$

$V_{k}^{\prime} \quad$ Molar volume of ketoprofen at the normal boiling point $\left(\mathrm{cm}^{3} \mathrm{~mol}^{-1}\right)$

$V_{\mathrm{m}} \quad$ Molecular volume of the growth unit of solute $\left(\mathrm{m}^{3}\right.$ molecule-1)

$V_{\text {solv }} \quad$ Partial molar volume of solvent $\left(\mathrm{m}^{3}\right)$

$T \quad$ Temperature $\left(\mathrm{K}\right.$ or $\left.{ }^{\circ} \mathrm{C}\right)$

$w_{\mathrm{k}} \quad$ Mass fraction of ketoprofen (kg ketoprofen ( $\mathrm{kg}$ solution $)^{-1}$ )

$x_{\mathrm{k}} \quad$ Molar fraction of ketoprofen ( $\mathrm{kg}$ ketoprofen ( $\mathrm{kg}$ solution $)^{-1}$ )

Greek letters

$\alpha_{1}, \quad$ Atomic angles $\left(^{\circ}\right)$

$\beta_{1}, \gamma_{1}$

$\alpha \quad$ Volume shape factor ( - )

$\beta \quad$ Surface shape factor $(-)$

$\Delta G_{\|}^{*} \quad$ Critical free-energy of formation of a cluster of size (J)

$\Delta T \quad$ Difference of temperature $\left({ }^{\circ} \mathrm{C}\right)$

$\gamma^{ \pm} \quad$ Activity coefficient of solute $(-)$

$\gamma_{\mathrm{k}} \quad$ Activity coefficient of ketoprofen in acetone + ketoprofen solution ( - )

$\mu \quad$ Viscosity of solution ( $\mathrm{Pa} \mathrm{s}$ )

$\mu_{\text {solv }} \quad$ Viscosity of pure solvant (Pas)

$\sigma_{\mathrm{s}} \quad$ Interfacial energy crystal-solution $\left(\mathrm{N} \mathrm{m}^{-1}\right)$

$\tau \quad$ Induction time (s)

$\xi \quad$ Shape factor $\xi=4 / 27 \times \beta^{3} / \alpha^{2}(-)$

\section{References}

[1] F. Espitalier, Ph.D. Thesis I.N.P., Toulouse, France, 1994.

[2] Sano, A., Kuriki, T., Kawashima, Y., Takeuchi, H., Hino, T., Niwa, T., Chem. Pharm. Bull. 37 (8) (1989) 2183-2187.

[3] Y. Kawashima, in: D. Chulia, M. Deleuil, Y. Pourcelot (Eds.), Powder Technology and Pharmaceutical Processes, Part 1, Chap. 14, Elsevicr, Amsterdam, The Netherlands, 1994, pp. 493-511.

[4] Allais, A., Rousseau, G., Meier, J., Deraedt, R., Benzoni, J., Chifflot, L., Eur. J. Med. Chem.-Chem. Ther. 9 (4) (1974) 381--389. 
[5] Briard, P., Rossi, J.C., Acta Crystallogr. C46 (1990) 1036-1038.

[6] Espitalier, F., Biscans, B., Peyrigain, S., Laguerie, C., Fluid Phase Equilib. 113 (1995) 151-171

[7] C. Laguerie lecture presented at the 'Working Party on Crystallization' of the European Federation of Chemical Engineering. Toulouse, France, 1992.

[8] D. Verdoes, Thesis Technishe Universiteit Delft, The Netherlands, 1991.

[9] J.W. Mullin, Crystallization, 3rd edn., Butterworth-Heinemann, London, England, 1993.

[10] Saxena, M.C., Gupta, M.P., Proc. Nat. Acad. Sci. India, 53(A) (II) (1983) 181-189.

111 W.A. House, Kinetics of crystallization of solids from aqueous solutions, in: R.G. Compton (Ed.), Comprehensive Chemical
Kinetics, Reaction at the liquid-solid interface, Elsevier. Amsterdam, The Netherlands, 1989 , p. 48.

[12] Turnbull, D., Cormia, R.L., J. Phys. 34 (1961) 820.

[13] R.C. Reid, J.M. Prausnitz, B.E. Poling, The properties of gases and liquids, 4th edn., Section 11, Diffusion Coefficients, McGraw-Hill, New York, 1987, pp. 577-626.

[14] T.K. Sherwood, R.L. Pigford, C.R. Wilke, Mass Transfer, McGrawHill, New York, US, 1975.

[15] B. Le Neindre, Viscosité, Techniques de l'ingénieur, Constantes physico-chimiques, K2, Techniques de l'ingénieur, Paris, France, 1990, pp. 480.21-480.22.

116] M. Petrissans, C. Gourdon, G. Casamatta, La mesure par l'image, 7 (24), Récents Progrès en Génie des Procédés, Nancy, France, 1993, pp. $79-84$. 